\title{
Sexualidade e Normas de Gênero em Revistas para Adolescentes Brasileiros'
}

\section{Sexuality and Gender in Magazines for Brazilian Adolescents'}

Daniela Barsotti Santos

Mestre em Psicologia pela Faculdade de Filosofia Ciências e Letras de Ribeirão Preto USP Professora do Centro Universitário Central Paulista (UNICEP).

Endereço: Avenida Guilhermina Cunha Coelho, 350, E-55, Bairro City Ribeirão, CEP 14021-520, Ribeirão Preto, SP, Brasil.

E-mail:danibarsotti®yahoo.com.br

\section{Rosalina Carvalho da Silva}

Professora Doutora da Faculdade de Filosofia Ciências e Letras de Ribeirão Preto USP e da Universidade de Franca (UNIFRAN).

Endereço: Rua Bernardino de Campos, 50, apto 802, Higienópolis, CEP 14015-130, Ribeirão Preto, SP, Brasil.

E-mail: rcdsilvaœffclrp.usp.br

I Este artigo foi originado da dissertação de mestrado defendida na FFCLRP-USP "Ideais de mulher: estética, visão de corpo e relações afetivo-sexuais veiculados pela mídia escrita em revistas direcionadas ao público jovem no contexto brasileiro", financiada pela CAPES.

\section{Resumo}

A mudança da relação tempo-espaço, provocada pelas novas tecnologias e expansão dos meios de comunicação, na globalização advinda da modernidade tardia, modificou a auto-identidade e reflexividade do eu. As bases de segurança constituintes da identidade são alteradas de forma dinâmica, conforme as próprias relações sociais são modificadas. A identidade, hoje, não pode ser considerada imutável. Torna-se cada vez mais conveniente apoiarem-se em receitas de estilos de vida, produzidas por vários setores sociais, que criam e difundem pela mídia verdadeiros manuais de como desenvolver uma auto-identidade. Nosso objetivo foi analisar ideais de feminilidade em matérias publicadas em duas revistas dirigidas ao público adolescente brasileiro, considerando aspectos ligados à sexualidade, à saúde sexual e às relações entre gêneros. Realizamos um estudo de caráter qualitativo, a partir de uma perspectiva de gênero. 0 corpus textual da pesquisa foi composto por matérias extraídas de 22 exemplares das revistas Capricho e Todateen. Identificamos três grupos nas seguintes temáticas: Beijo e "amasso"; Início da vida sexual; e Práticas Sexuais. Ambas as revistas abordam ideais de relações entre gêneros que perpetuam padrão tradicional dicotômico. As matérias prescrevem atitudes e comportamentos femininos que, apesar de parecerem diferentes e avançados, visam à manutenção de um padrão de gênero, no qual a iniciativa feminina nesta perspectiva envolve o "jeitinho feminino", isto é, ações indiretas de manipulação que podem dar ao rapaz a impressão de ter sido ele o idealizador da ação posta em prática. Esses dados parecem particularmente importantes quando pensamos em programas de saúde dirigidos a esse segmento populacional.

Palavras-chave: Ideais de feminilidade; Sexualidade; Saúde Sexual; Adolescência; Gênero e Mídia. 


\section{Abstract}

The change in the relation of space and time caused by new technologies and by the media expansion, in the globalization that has derived from the late modernity, has modified the identity and reflexivity of the "self". The security foundations that constitute the identity are dynamically altered as the social relations are modified. Today the identity cannot be regarded as immutable. Thus, it becomes increasingly convenient to support it by means of recipes of lifestyles, produced by various social sectors that create and disseminate, through the media, manuals on how to develop a self-identity. Our objective was to analyze the ideals of femininity in articles published in two magazines for Brazilian teens, considering aspects of sexuality, sexual health and relationships between genders. We performed a qualitative study based on a gender perspective. The research corpus was composed of articles extracted from 22 issues of the magazines Capricho and Todateen. Three groups were identified in the following themes: Kiss and squeeze, Beginning of sexual life, and Sexual Practices. Both magazines approach ideals of relations between genders that perpetuate traditional dichotomic standards. The articles prescribe feminine attitudes and behaviors, which despite seeming different and advanced, are designed to maintain a gender standard in which the feminine initiative involves the "jeitinho feminino": indirect actions of manipulation that can give the boy the impression that he was the one who had the idea that was put into practice. These data seem particularly important when we think of health programs targeted at this segment of the population.

Keywords: Femininity Ideals; Sexuality; Sexual Health; Adolescence; Gender and Media.

\section{Introdução}

Atualmente, os meios de comunicação em massa ganham destaque devido ao aumento da velocidade, abrangência geográfica e variedade com que seus produtos têm circulado por todas as sociedades na modernidade tardia (Thompson, 1990). A mídia pode ser considerada uma forma de poder simbólico conjuntamente às outras formas de poder: econômico, político e coercivo, principalmente militar. Os meios de comunicação conseguem ser a principal forma propagadora de ideologias das camadas dominantes, além de serem reprodutores de jogos de poder que podem aquilatar ou estigmatizar determinados valores ou mesmo segmentos sociais (Thompson, 2002). Estendendo-se por ideologias, nesse caso, os conjuntos de significados e sentidos existentes na vida social que atuam como corpos de idéias de determinados grupos ou camadas sociais; conjunto de crenças orientadas para a ação; e como veículo pelo qual as pessoas entendem os seus mundos (Xavier, 2002).

A mudança da relação tempo-espaço, provocada pelas novas tecnologias e expansão dos meios de comunicação, a globalização e o capitalismo advindos da modernidade tardia modificaram a auto-identidade e a reflexividade do eu. Nesse sentido, as bases de segurança ontológica e de risco, constituintes da identidade, são alteradas de forma dinâmica conforme as próprias relações sociais vão sendo modificadas (Giddens, 2002; Dubar, 2002).

A identidade, hoje, não pode mais ser considerada como o estado do que não muda, do que fica sempre igual ou a consciência da persistência da própria personalidade, como definem alguns dicionários. Para Kellner (2001):

(...) segundo a perspectiva pós-moderna, à medida que o ritmo, as dimensões e a complexidade das sociedades modernas aumentam a identidade vai se tornando cada vez mais instável e frágil. Nessa situação, os discursos da pós-modernidade problematizam a própria noção de identidade, afirmando que ela é um mito e uma ilusão. É possível ler tanto em teóricos modernos, tais como os da escola de Frankfurt e Baudrillard, quanto em outros teóricos pós-modernos que o sujeito autônomo e autoconstituído, realização final do indivíduo moderno, de 
uma cultura do individualismo, está se fragmentando e desaparecendo devido aos processos sociais que nivelam as individualidades na sociedade racionalizada, burocratizada, consumista e dominada pela mídia (Kellner, 2001, p. 298).

Bauman (2005) afirma que as pessoas, em busca de identidade, vêem-se invariavelmente diante da tarefa intimidadora de alcançar o impossível: "Tornamonos conscientes de que o 'pertencimento' e a 'identidade' não têm solidez de uma rocha, não são garantidos para toda a vida, são bastante negociáveis e revogáveis [...]" (p. 17).

Assim, torna-se cada vez mais conveniente para as pessoas apoiarem-se em "receitas de estilos de vida" que são produzidas por vários setores da sociedade. Dentre esses, podemos destacar os vários segmentos do mercado que criam e difundem pela mídia verdadeiros manuais de como desenvolver uma auto-identidade "segura" e viver a própria vida. Muitas matérias veiculadas na mídia tentam dar conta dos mais diferentes setores da vida humana. A saúde e a vida social relacional são constantemente abordadas, provavelmente por serem as mais buscadas nos diferentes tipos de mídia. As matérias veiculadas sobre estilos de vida acabam ditando formas de como vivenciar o próprio corpo, de como devem ser as relações com os outros e com a própria sexualidade, entre tantos outros aspectos. Isso permite dar contornos de pertencimentos e de identidade que, por serem móveis, fluidas, exigirão sempre complementações e atualizações. Essa produção de conteúdos é criada por demandas sociais, necessidades que estão sempre emergindo pela instabilidade de nossas identidades e nossas posições sociais e que, ao serem sanadas, sempre parcialmente, criam outras demandas úteis ao mercado.

Em relação à mídia escrita, na atualidade, observamos um grande número de publicações periódicas, dirigidas aos mais diferentes segmentos populacionais. Muitas delas dirigidas aos diferentes grupos etários da juventude. Fase em que, ao que indicam muitos estudos (Strasburger, 1999; Marcello, 2005), a influência da mídia parece ser mais contundente. Jovens e adolescentes encontram-se, de forma geral, num período de desenvolvimento no qual os modelos exer- cem grandes influências em seus processos identitários. Nesse processo, a mídia ganha uma importância maior devido ao aumento de produtos simbólicos disponibilizados em nossas sociedades atuais nas quais parece haver menos tempo para reflexões.

São muitos os estudos sobre a influência da mídia na juventude. Miranda-Ribeiro e Moore (2002) estudaram como a saúde reprodutiva é abordada por seções das revistas Capricho e Querida, dirigidas ao público juvenil. O estudo ressalta o caráter normativo que algumas matérias das revistas possuem em relação aos comportamentos sexuais e práticas de sexo seguro. Outros estudos mostram que, além de normativas, as informações mostravam-se ambíguas, como no caso estudado por Serra e Santos (2003), no qual fizeram uma análise dos conteúdos de uma revista para adolescentes ${ }^{2}$ que abordava as práticas alimentares de emagrecimento.

Ao estudar estereótipos raciais e de gênero em comerciais de televisão, Roso e colaboradores concluem:

Em um mundo onde a globalização tem sido cada vez mais imposta às pessoas - seja através de propagandas ou de qualquer outro meio - precisamos parar, pensar e refletir se o que realmente queremos é uma população de andróides, ou se queremos que as culturas (e sub-culturas) sobrevivam. A tentativa de padronizar vestimentas, tecnologias, modo de viver, de pensar e agir não é somente discriminação ou exclusão; é reforçar uma moral estética e esquecer da ética na produção de formas simbólicas. O intuito é obter grandes vendas e lucro, assassinando culturas, massificando, cada vez mais, as pessoas (Roso e col., 2002, p. 90).

Podemos pontuar o caráter sócio-histórico presente tanto nos conteúdos midiáticos como em diversas abordagens metodológicas empregadas em trabalhos de análise de conteúdos midiáticos dirigidos à mulher e à adolescência feminina na imprensa brasileira, estudando temas como a perda da virgindade; representações de sexualidade; ideais de relacionamentos afetivo-sexuais; ideais de estética; maternidade; ideais de mulher; feminismo; e profissão: Buittoni (1981); Bassanezi (1993, 1997); Bassanezi e Usini (1995); Oliveira (2005); Santos (1986); Sarti e Moraes (1980); 
Matos (2002); Navarro-Swain (2001); Fraga (2003); Figueira (2003); Andrade (2003); Couthard-Caldas (2005); Marcello (2005); Sgarbieri (2005), Couto e Menandro (2003). Além disso, notamos por meio desses trabalhos que existem discursos divergentes entre si, publicados simultaneamente nas matérias das revistas estudadas. Entretanto, percebemos que a mídia participa ativamente nas pautas dos processos identitários.

Pensando na participação que a mídia possui na produção e reprodução de formas simbólicas - entre elas, as relações entre gêneros -, na sua abrangência cada vez maior, sobretudo na sua influência na vida das pessoas em geral e, particularmente, na vida de adolescentes; propusemo-nos a realizar este estudo que tem a intenção de poder contribuir com programas de promoção de saúde dirigidos à juventude, além de subsidiar discussões acerca das posições idealizadas que são impostas às mulheres, principalmente jovens, no contexto brasileiro.

\section{Objetivo}

Analisar os ideais de feminilidade, ou seja, os modos e formas previstos de ser mulher, explicitados ou subentendidos, em matérias publicadas em duas revistas dirigidas ao público adolescente em circulação no Brasil, considerando aspectos ligados à sexualidade, à saúde sexual e às relações entre gêneros.

\section{Abordagem Teórico-Metodológica}

Neste trabalho, adotamos uma das abordagens metodológicas qualitativas de pesquisa, cuja perspectiva teórica deriva das ciências sociais, que, entre outras características, busca e prioriza as compreensões dos aspectos que possam estar direta ou indiretamente ligados às questões que se pretende estudar, em vez de priorizar explicações causais e suas possibilidades de generalizações (Weber, 1993; 1995). Ou seja, tratase de um estudo de natureza qualitativa que assume algumas posturas referentes aos paradigmas pós-positivistas e pós-modernos, que se diferenciam muito das ciências sociais convencionais e buscam responder a questões semelhantes às ciências da natureza (Denzin e Lincoln, 200o). O método de pesquisa, nessa perspectiva, não deve mais ser tratado como um conjunto de regras universalmente aplicáveis ou como abstrações teóricas. As questões metodológicas es- tão entrelaçadas ao que se considera ser a natureza ou às particularidades do que vai ser tratado e às perspectivas particulares de análises adotadas (Denzin e Lincoln, 200o). A análise de dados adotada neste trabalho é derivada das filosofias interpretativistas (Schwandt, 200o; Silverman, 200o). Buscamos realizar análises interpretativas que, como afirmam Deslandes e Gomes, 2004 , operam por recortes e suas leituras são orientadas por determinados aportes teóricos. Neste estudo, compreendemos que o trabalho de interpretação se dá sobre dados já interpretados, produzidos ou construídos pelas pessoas em suas falas ou textos.

No tipo de pesquisa qualitativa aqui adotada, o marco teórico é tomado apenas como referencial. Isto quer dizer que o marco referencial deve ser a fonte para a análise e nunca um modelo teórico no qual se deve forçar a localização de nossa investigação. Servirá para contrastar, em um segundo momento, nossas reflexões com as de outros autores e, assim, as entender melhor, sem forçar ou impor uma interpretação.

Para analisar os ideais de mulher subjacentes aos conteúdos midiáticos, utilizamos o enfoque de gênero, proposto fundamentalmente por Scott (1988), como marco teórico. Nos últimos vinte anos, foram realizados inúmeros estudos sobre relações de gênero. No entanto, no nosso ponto de vista, o marco conceitual mais importante para os estudos de gênero continua sendo o enfoque proposto pela historiadora. Para a autora, gênero é uma categoria de análise útil para estudar as relações de poder impostas ao feminino e ao masculino por meio de discursos, que estão sendo constantemente construídos histórico-socialmente. Relações de poder que, como tal, podem ser entendidas como assimétricas. Ao considerarmos gênero como referência para um estudo sobre os ideais de feminilidade subjacentes aos conteúdos midiáticos, devemos considerar, como propõe Scott, símbolos (estereótipos e contrastes), conceitos normativos que estão sendo empregados para decodificar tais símbolos e como essas normas estão sendo transmitidas. E, ainda, como acrescenta Louro (1997), ao comentar a análise proposta por Scott, deve-se dar atenção a como são feitas as descrições das relações dicotômicas entre mulheres e homens e considerar ainda a multiplicidade e a gama de variações de masculinidades e feminilidades. 


\section{Procedimentos Metodológicos}

\section{Descrição, seleção e categorização do material}

O corpus textual da pesquisa foi composto por matérias extraídas de 22 exemplares das revistas femininas para adolescentes Capricho e Todateen, publicadas no período de junho a dezembro de 2002.

Utilizamos a mídia escrita como fonte de nossa investigação por oferecer um rico material para análise, além de possuir fácil acessibilidade e armazenamento. A constituição do corpus, que como salienta Barthes (1967 apud Bauer e Aarts, 2002, p. 44) “... é uma coleção finita de materiais determinada de antemão pelo analista, com (inevitável) arbitrariedade", ocorreu seguindo a idéia de composição de uma amostragem teórica, que segundo Flick (2002) deve buscar um conjunto de dados empíricos que representem bem o universo que se deseja estudar. Dessa forma, a seleção de materiais se esgota quando o que está sendo inicialmente analisado mostra repetições em seus padrões. Nesse sentido, o primeiro passo para seleção de materiais consistiu na leitura geral das matérias publicadas, buscando-se identificar a reiteração dos temas eleitos para a pesquisa: ideais de mulher considerando aspectos da sexualidade, saúde sexual e relações entre gêneros.

A revista Capricho ${ }^{3}$ é a líder do segmento e tem uma tiragem de 153.710 exemplares, com periodicidade quinzenal, sendo distribuída por todo o território nacional (Editora Abril, 2003) Já a revista Todateen ${ }^{4}$ é a terceira revista mais vendida, com a tiragem de 150.00o exemplares, possui periodicidade mensal e distribuição nacional (Editora Alto Astral, 2003; Grupo de Mídia de São Paulo, 2003). Essas revistas foram selecionadas por oferecerem um maior número de matérias com temáticas pertinentes aos nossos objetivos, semelhantes entre si, porém com abordagens diferentes.

\section{Procedimentos para a análise dos dados}

Para a análise de dados seguimos fundamentalmente os procedimentos de sistematização propostos por vários autores para a realização de análises descritivas interpretativas (Navarro e Díaz, 1995; Valles, 1997; Flick, 2002; Ritchie e Spencer, 2002).
Realizamos uma ampla leitura das revistas e selecionamos propositalmente as seções e subseções cujas temáticas eram: aspectos da sexualidade, informações sobre saúde sexual e relações entre gêneros. Foram sete as seções eleitas para o estudo. Destas, três da revista Capricho (Sexo, Vida real, Receita); e quatro seções da revista Todateen (Amor, Sexo/ Seu Corpo, Tintim por tintim, Sexo 100 vergonha). Assim, fizemos uma primeira redução de dados, perfazendo um total de 37 matérias.

Após a seleção dessas seções, fizemos uma nova leitura dessas matérias e as dividimos em categorias temáticas por similaridade de conteúdos. Identificamos os temas centrais de cada matéria, distribuídos nas seguintes categorias por similaridade das temáticas abordadas: Beijo e "Amasso"; Início da Vida Sexual; e Práticas Sexuais com o uso do preservativo. Desse modo, realizamos uma segunda redução de dados.

A partir dessa nova seleção, passamos a realizar novas leituras buscando a identificação e codificação de trechos das matérias que entendemos como interessantes e significantes para percebermos como estavam tratando os ideais de condutas femininas.

\section{Resultados e Discussão}

\section{Beijo e Amasso}

Das 37 matérias selecionadas, identificamos cinco cujos temas abordavam aspectos que envolviam o beijo e a troca de carícias sem o intercurso sexual, ou seja, o "amasso". Tanto na revista Capricho como em Todateen, o beijo é conceituado como um ato natural e atrelado à afetividade. Apesar disso, essa "naturalidade" é um tanto questionável, uma vez que ambas as revistas publicam matérias em forma de manuais de conduta que prescrevem modos de obtenção de um beijo considerado "bom".

Na seção Receita, da revista Capricho, a matéria "Como... beijar... gostoso" (Capricho, 2002c, p. 88) conta com a participação de três rapazes de 16 a 18 anos que oferecem dicas "passo-a-passo" de como gostam de ser beijados. A matéria é escrita sob forma de 14 tópicos em que os rapazes explicitam detalhadamente o que a garota deve fazer para "beijar bem". Tanto os rapazes quanto a matéria enfatizam que a existência

3 Publicada pela Editora Abril, em São Paulo, desde 1952.

4 Publicada pela Editora Alto Astral, em Bauru-SP, desde 1994. 
de afeto entre as pessoas envolvidas torna o beijo melhor. Na mesma matéria, o redator destaca um quadro com dicas de como a jovem pode reconhecer se o parceiro está gostando do seu beijo. Apresenta ainda algumas situações que exemplificam possíveis reações negativas: "ele dá mais selinho do que beijo de língua, começa a bater papo e não pára de falar”.

A revista Todateen publicou o "Manual do beijo gostoso - Roteiro para deixar o garoto louco pelos seus beijos."(Todateen, 2002b, p.36). Semelhante à matéria de Capricho, esse manual foi elaborado por uma jornalista da revista em forma de tópicos e dividido da seguinte maneira: "informações técnicas", com dicas de como conservar um bom hálito, de como cuidar da pele dos lábios e, a seguir, aconselha as leitoras a não usar um batom de cor forte, pois os meninos não gostam no momento do beijo. No segundo tópico do manual, denominado "modo de usar", são apresentados dois textos, um direcionado para garotas que nunca beijaram, denominadas "boca virgem - $B V$ " e outro para garotas que já beijaram na boca, "boca não-virgem".

É interessante notar que os dois manuais focam o bom desempenho da garota para agradar ao rapaz que será beijado e, a partir de sua performance, seduzi-lo. Como exemplo disso, no caso de Todateen: "Manual do beijo: tudo para você deixar o gato amarradão no seu ato de tocar os lábios e fazer uma leve sucção (oba!)". E em Capricho: "Faça joguinho: $\varepsilon$ bom você parar de beijar no auge do beijo para deixálos babando".

Apesar de recomendarem a existência do afeto entre as pessoas que se beijam, somente a revista Capricho tece alguma consideração sobre algum tipo de relacionamento afetivo-sexual e alerta suas leitoras de que apenas um bom beijo não lhes assegura um namorado: "Só mais uma coisa: beijo bom não faz o cara querer namorar. Eles dizem que para ter algo sério é essencial gostar de conversar com a garota, se sentir à vontade ao lado dela”.

Em outra matéria de Capricho, "Era só o que faltava - Um guia avançado para quem quer ir além dos beijos, abraços e aperto de mão" (Capricho, 20oza, p. 44), apresenta-se um manual com sugestões dadas por uma professora de "artes sensuais" 5 para o casal diversificar a maneira de acariciar e beijar. A matéria apresenta um quadro lateral no qual as jovens da "Galera Capricho" ${ }^{6}$ dão as suas impressões sobre a dica que elas mais gostaram. Outro quadro oferece tópicos com exercícios para aumentar o controle sobre a própria língua com a intenção de melhorar a qualidade do beijo. Segundo a matéria, o conteúdo foi retirado de um livro que ensina técnicas de performance sexual e sensual ${ }^{7}$. Na mesma matéria, quatro rapazes de 18 a 20 anos relatam sobre a "coisa mais original" que uma garota fez com eles durante o "ficar". Outro quadro sugere dicas de massagem nos pés e nas mãos, oferecidas por dois especialistas em técnicas de massagem ${ }^{8}$.

Podemos considerar, a partir das matérias citadas anteriormente, que os textos denotam uma preocupação com as técnicas para se obter uma performance satisfatória no beijar e nas carícias sem o intercurso sexual ("amasso") com a finalidade, sobretudo, de a garota agradar ao parceiro.

Em outras matérias, como: "Amasso com sentimento é muito melhor - Capricho amassa dez meninos e meninas numa sala para debater o assunto. Uma boa chance para você entender melhor a cabeça dos meninos" (Capricho, 2002b, p. 26), a redação da revista Capricho promove um debate entre jovens com a finalidade de colher opiniões masculinas e femininas sobre o "amasso".

Diferentemente dos manuais descritos anteriormente sobre o beijo e o amasso, que se propunham a ensinar técnicas para agradar o garoto, a matéria da revista Capricho procurou levantar opiniões e julgamentos morais de garotos e garotas a respeito do "amasso".

O jornalista comenta que existe uma dualidade entre a "tradição e a modernidade" presente na opinião dos dois grupos. Podemos exemplificar o contraste de opiniões ao qual o jornalista se refere neste trecho da matéria:

\footnotetext{
5 Nelma Penteado.

6 "Galera Capricho": Todo ano a revista seleciona um grupo de moças e rapazes para realizarem um estágio na revista. Esses jovens participam de matérias como entrevistados, experimentam e fornecem opiniões a respeito de roupas e produtos cosméticos e escrevem algumas matérias da revista.

7 Walfrido, V.de Toque sensual, Ediouro.

8 Jorge Uehara e Priscila Pitt, especialistas em shiatsu e reflexologia.
} 
(jornalista): Amasso na balada é sinônimo de aloprar ${ }^{9}$ a menina?

L. e A. (rapazes): É, aloprar.

M. e R. (garotas): (juntas) E, quando você sabe que a mina gosta de você?

A. (rapaz): Aí eu mantenho um contato. Se ela me ligar, eu atendo. Se ela falar vem aqui em casa, eu vou.

M. (garota): Então vocês se aproveitam?

A. (rapaz): Vai que eu estou num dia ruim.

M. (garota): E a mina passa a ser estepe?

L. e A. (rapazes): É.

M. (garota) Aí você está iludindo a mina.

D. (rapaz): Ela que se ilude.

M. (rapaz): Se ela deu a liberdade de já chegar amassando...

M. (garota): Mas se ela gosta do cara, não é normal?

M.(rapaz): Não é porque você gosta do cara que vai chegar dando um amasso. Gostar não é amasso.

R. (garota): Você pode gostar e querer um amasso porque sente tesão pelo cara.

M. (rapaz): Tudo bem, tudo bem, mas gostar não é só amasso.

D. (rapaz): Se você gosta, pensa duas vezes antes de fazer uma besteira. Se ela quer conhecer, então conheça direito. Não chega no amasso direto. [...]

(CAPRICHO, 2002b, p. 27).

De fato, podemos concordar com a afirmação inicial do autor da matéria, uma vez que os rapazes entrevistados transmitem em suas opiniões uma delimitação clara de distinção de gênero e "dupla moral sexual” em relação à sexualidade em que teoricamente rapazes sempre estão disponíveis a qualquer atividade de cunho sexual, não importando quem seja a parceira. 0 sentimento amoroso também é abordado por estes que consideram que um rapaz preservará a garota de quem gosta de investidas mais ousadas. Além disso, aconselham as garotas que estejam apaixonadas em adiarem o amasso a fim de conhecer melhor o rapaz.
Já as garotas que foram entrevistadas concordam com a ação feminina de dar o amasso com um rapaz por quem sintam “tesão", porém, diferentemente dos rapazes, a atração sexual é ligada ao sentimento amoroso: "R. (garota): Não existe só sentimento ou só tesão. Se você tem sentimento é porque você já tem tesão”.

A partir das matérias vistas acima, podemos afirmar que os rapazes participantes emitem suas opiniões e relatos de experiência sobre o que lhes agrada no beijar e no amasso, sobrando pouco espaço para a expressão da satisfação e voz feminina.

Todas as matérias citadas acima fazem a ligação do beijo e do amasso ao sentimento amoroso entre os parceiros, embora as vozes masculinas impressas transmitam a possibilidade de separação desses elementos. Podemos considerar que o amor ainda está relacionado às construções femininas de sexualidade num ideal de mulher difundido por esses materiais midiáticos. Essa assimetria sexual-afetiva é comentada por Lipovetsky (200o) da seguinte maneira:

Isso significa dizer que, na linha direta do passado histórico, o amor continua a ser uma peça constitutiva da identidade feminina. $\mathrm{O}$ avanço dos valores democráticos encetou uma reivindicação cada vez mais forte de apropriação de si em matéria de vida profissional, familiar e sexual, mas não aboliu de modo algum a demanda passional feminina, a qual significa, nesse plano, certo desejo de desapropriação de si. De um lado, aumentam as exigências femininas de posse de si como sujeito social, do outro se reproduzem expectativas de "desapossamento" subjetivo em matéria de vida afetiva. 0 feminino se constrói, de agora em diante, na conjunção dos desejos de controle do destino individual e dos desejos de entrega emocional interpretados como estrada real rumo a uma vida rica e plena (p. 32-33).

Para o autor, o amor passou a ser um elemento altamente desejável para a construção do feminino, diferentemente do passado, em que os sentimentos amorosos eram considerados parte inerente do ser mulher.

A conquista do afeto do outro através da sedução é um dos principais objetivos das jovens, o que se refle-

9 Dicionário Houaiss: aloprar acepções: verbo. Regionalismo: Brasil. Uso: informal. intransitivo

1. tornar-se inquieto, agitado; intransitivo 2. ficar maluco; endoidecer 
te nas técnicas de performance sugeridas pelas matérias discutidas. É interessante observar que as leitoras são alertadas a respeito da necessidade de complementar suas performances através de outras técnicas como, por exemplo, se fazer de difícil.

Também podemos observar essa assimetria sexualafetiva no próximo tópico.

\section{Início da vida sexual}

Selecionamos 21 textos nos quais identificamos temas que envolvem o início da vida sexual, porém, para este estudo, nos ateremos a dois temas que foram abordados em matérias da revista Todateen e se intitulam: "Sexo: prova de amor? Não caia nessa armadilha." (Todateen, 2002a, p. 76) e "Sexo: depois da primeira vez. Como essa experiência muda a sua vida." (Todateen, 2002c, p. 76). Ambas as matérias foram publicadas na seção Sexo/Seu Corpo.

A primeira matéria consiste num texto cursivo, elaborado por uma jornalista da revista, que contém relatos de garotas que consideram estar arrependidas por iniciarem a vida sexual após ceder à pressão de seus namorados ou de amigos. A autora da matéria considera fazer parte da "natureza" masculina o rapaz ter pressa em ter relações sexuais com sua namorada:

O que fazer agora? É da natureza masculina ter pressa para chegar aos "finalmente", mas você não tem que passar por cima dos seus sentimentos só para calar os hormônios que estão "gritando" dentro do menino. Se, na hora de levantar a plaquinha com o sinal vermelho, ele vier com aquele papinho de que transar é sinônimo de confiança, amor eterno e coisas assim, atenção: você está diante de uma cilada, gatinha! (Todateen, 2002a, p. 76)

O texto ainda destaca a responsabilidade da leitora por seu próprio corpo: "Por isso, faça só o que tiver vontade, porque o corpo é seu!", e aconselha a leitora que exponha seu ponto de vista, e, caso o rapaz continue a insistir, é indicado à garota que termine o namoro. Outra possibilidade é considerada na matéria: neste caso, o texto recomenda que a garota exponha sua indecisão e peça "um tempo" ao rapaz até sentir-se pronta para ter o primeiro intercurso sexual.

A matéria aborda dois pontos interessantes. 0 primeiro ponto consiste na atribuição que o texto faz de uma característica fixa de masculinidade, explicada por meio de uma "natureza masculina" influenciada por hormônios. Tal "natureza masculina” é legitimada por uma visão biologicista e determinista, que Badinter (1993) considerou como forma aprisionadora do homem ao eterno masculino:

O essencialismo desemboca necessariamente na separação e, pior ainda, na opressão. Ele só pode oferecer uma perspectiva limitada da natureza e das potencialidades humanas. Tudo está inscrito por antecipação, sem possibilidade de mudanças ou de criação. Prisioneiros de um esquema predeterminado e mesmo supradeterminado, homem e mulher estão condenados a desempenhar para sempre os mesmos papéis (p. 27).

Outro aspecto notável presente na matéria é que, a partir da definição de essência masculina, também é sugerido à leitora a promoção do diálogo como forma de resolução do dilema suscitado pela pressão exercida pelo rapaz. E caso não haja um acordo satisfatório, a possibilidade do término do namoro é considerada pelo texto, que reitera à leitora a posição de detentora de seu próprio corpo.

Podemos observar novamente a preocupação em promover a assertividade feminina na matéria: "Sexo: Depois da primeira vez. Como essa experiência muda a sua vida?". A matéria consiste em tópicos com dicas de como proceder diante de alguns aspectos referentes ao início da vida sexual, apresentando as vantagens e desvantagens de tais circunstâncias.

A matéria sugere o uso do preservativo como forma de proteção a doenças sexualmente transmissíveis e prevenção a uma gravidez indesejada. Além disso, associa o uso do preservativo a uma atitude responsável em relação ao próprio corpo, colocando a garota no lugar de principal pessoa a ser prejudicada caso haja contaminação por uma DST ou venha a conceber uma criança. 0 texto não cita a responsabilidade do parceiro ou qualquer forma de negociação alternativa pelo uso de preservativos com este, a não ser a impositiva. Outro aspecto da matéria consiste no reforço da prevalência da vontade feminina, caso haja pressão por parte do rapaz em ter mais intercursos sexuais. É importante ressaltar a recomendação da matéria para que a leitora iniciante sexualmente visite o ginecologista, para que este complemente informações sobre saúde reprodutiva e sexual, realize exames preventivos e indique o tratamento adequado caso haja alguma doença. 
Podemos considerar que ambas as matérias discutidas aqui propõem às leitoras o início de uma vida sexual pensada e desejada para o próprio bem-estar, independentemente do tipo da relação afetiva com o parceiro. A responsabilidade pelo próprio corpo é lembrada pelos textos. Além disso, podemos pensar nessa ênfase dada pelos textos como sendo um produto dos esforços do movimento feminista na sociedade brasileira, a partir da década de 1970, em obter maior reflexão e liberdade de escolha feminina acerca de sua vida sexual e reprodutiva. 0 movimento feminista se utilizava bastante da frase: Nosso corpo nos pertence. Para Ávila e Correa (1999, p. 73) a conotação sugerida pela frase é:

A idéia de reapropriação do próprio corpo contida na afirmação nosso corpo nos pertence se ancora no reconhecimento de que o corpo de cada uma/ um é o lugar primeiro da existência humana, lugar partindo do qual ganham sentido as experiências individuais no cotidiano e nos processos coletivos da história.

Entendemos que as matérias discutidas procuram dar essa perspectiva às suas leitoras para que tenham uma vida sexual satisfatória e autônoma, contudo, ao mesmo tempo, essas mesmas matérias colocam o rapaz numa posição fixa, biologizante, cristalizada, e até de certa forma não possuidor dessa mesma autonomia sexual que é proposta às garotas; ele parece ser vítima de seus "instintos masculinos".

\section{Práticas sexuais e o uso do preservativo}

Identificamos em nosso trabalho 11 matérias que envolviam temas relacionados às práticas sexuais e ao uso do preservativo. Entendendo aqui práticas sexuais como todo tipo de ação realizada para obtenção de prazer sexual, seja a masturbação, o ato sexual pênisvagina, o sexo oral e anal. Destacamos para este estudo uma matéria que consideramos representativa para a discussão deste tópico.

Nas duas revistas, são divulgados dados obtidos e interpretados a partir de pesquisas realizadas por instituições nacionais e internacionais. São divulgados dados, principalmente estatísticos, sobre comportamentos sexuais e prevenção em saúde na juventude. Na revista Capricho, em sua seção Vida Real, foi publi- cada uma matéria sobre o dia mundial de combate à Aids $\left(\mathrm{n}^{0} .902\right.$, p. 8) que apresentava dados sobre a Aids no Brasil e no mundo, enfatizando seu impacto sobre os jovens e fornecendo um breve histórico sobre a Aids, afirmando o comprometimento da linha editorial da revista na campanha de combate e prevenção à Aids (a campanha "Camisinha: Tem que Usar").

Com relação ao uso do preservativo, consideramos que as revistas abordam as questões com informações adequadas, porém de forma pouco dialógica. As relações entre gêneros têm um papel importante, sobretudo na negociação do sexo seguro e na responsabilidade da prevenção das DSTs, HIV e Aids. No entanto, nesse aspecto, os textos das revistas dão pouco espaço para essa discussão. Eles são taxativos no modo de a jovem abordar o uso do preservativo. A garota deve exigir o seu uso e se recusar a fazer sexo caso o parceiro se negue a usá-lo, como podemos ver no exemplo: “... a Aids continua uma doença grave, um tremendo motivo para você dizer 'Não' ao ficante ou ao namorado que insistir em deixar a camisinha dentro da carteira" (Capricho, 2002c, p. 8).

Ambas as revistas revelam a preocupação de lembrar às suas leitoras a respeito da prevenção de DSTs, mesmo em relacionamentos estáveis e aparentemente monogâmicos, uma vez que mulheres monogâmicas heterossexuais com relacionamentos estáveis vêm alcançando os maiores níveis de contaminação por HIV no mundo, desde os anos 1990, e esta vulnerabilidade pode ser maior em jovens mulheres que iniciam a vida sexual. No entanto, sabemos que informações apenas impositivas podem divulgar um ideal, mas podem falhar em seu intento ao desconsiderar as questões culturais. Estudos como o de Heise e Elias (1995) pontuam essa dificuldade, como vemos no trecho que traduzimos abaixo:

Existem também fortes barreiras emocionais que impedem mulheres de levantar o tema do uso do preservativo. Especialmente no contexto de um relacionamento em andamento, discussões sobre preservativos geralmente despertam questões dolorosas de fidelidade e confiança que muitas mulheres e homens não gostariam de confrontar. (Heise e Elias, 1995, p. 936) ${ }^{10}$

10 "There are also strong emotional barriers that prevent women from raising the subject of condom use. Especially in the context of an ongoing relationship, discussion of condoms often raises painful issues of fidelity and trust that many women and men would rather not confront." 
Todos os aspectos ligados ao conhecimento sobre o uso, disponibilização e informações relacionadas ao preservativo demonstram preocupações legítimas, por parte de ambas as redações, em cumprir um papel informativo e esclarecedor, em consonância com as políticas públicas de prevenção às DSTs. Porém, embora existam mensagens dirigidas às leitoras a respeito da autonomia que elas devam ter sobre seus próprios corpos, as matérias pouco tratam dos diálogos entre parceiros. Os textos são taxativos, restando pouco espaço para discussões e reflexões.

Acreditamos que apesar do considerável aumento da qualidade e do volume de informações sobre saúde reprodutiva e sexo seguro, ainda se forma uma lacuna quando o assunto é a proposição de reflexões. Consideramos haver um contraste no que se refere à abordagem de gêneros frente à sexualidade, uma vez que os garotos ainda são retratados de uma forma cristalizada, fixa e aparentemente imutável. Em contrapartida, as garotas recebem uma abordagem diversa em que ocorre a valorização de uma expressão de sexualidade responsável e autônoma, mas pautada por normas descritas em manuais, prejudicando assim a reflexão sobre a diversidade envolvida na relação de gênero.

É necessário atentar para o fato do quanto a mídia, em suas diferentes modalidades, utiliza a interpretação parcial de resultados de pesquisas, muitas vezes questionáveis em termos científicos, para difundir ideais de estilos de vida saudáveis.

O movimento de promoção de saúde, pensado como um processo de capacitação da comunidade para atuar na melhoria de sua qualidade de vida e saúde, inclui desde seu início a idéia de adoção de estilos de vida saudáveis. Mas inclui também a necessidade de uma maior participação no controle do processo social, no qual os indivíduos e grupos devem saber identificar suas aspirações, satisfazer necessidades e modificar favoravelmente o meio ambiente.

Desde a primeira conferência internacional, cujos resultados foram divulgados na Carta de Ottawa, são identificados cinco campos de ação para a promoção de saúde: construção de políticas públicas saudáveis; criação de ambientes favoráveis à saúde; desenvolvimento de habilidades pessoais e sociais para mudança de estilos de vida; reforço da ação comunitária; e reorientação dos serviços de saúde. As demais conferências internacionais tomam esta primeira carta como base e vão acrescentando os aspectos que devem ser reforçados e acrescentados (Brasil, 2002). Apesar desses cinco campos, a ampla divulgação se dá mais especificamente em relação a um deles: o desenvolvimento de habilidades para mudança de estilos de vida com uma forte tendência de responsabilizações pessoais, individuais, de estados saudáveis e de bem-estar em geral (Marcondes, 2004). A Mídia se apropria dessa dimensão e privilegia a divulgação destes "estilos de vida" para satisfazer as necessidades de pautas de condutas que nos dêem possibilidades de identidades e pertencimentos.

\section{Considerações Finais}

Este estudo teve como objetivo analisar os ideais de feminilidade, considerando aspectos da sexualidade, saúde sexual e relações entre gêneros. Ao utilizarmos o referencial de gênero para a análise do material em questão, pudemos considerar que tanto a revista Capricho quanto a revista Todateen trazem em suas matérias mais de um ideal de mulher ou de feminilidade. Ambas abordam em seus conteúdos idéias diversas, e algumas vezes contrastantes, do que é ser mulher e do que é feminilidade, sendo difundido, praticamente, apenas um ideal de masculino e de masculinidade.

De modo geral, as relações entre gêneros difundidas no material analisado perpetuam um padrão tradicional, tal como observamos em outros estudos sobre revistas femininas, apresentados anteriormente neste trabalho. Nesse padrão observado de relação entre gêneros, há a valorização da heterossexualidade, de relacionamentos duradouros e monogâmicos, com a valorização do amor romântico para mulheres. As matérias conservam um padrão dicotômico de gênero, denotando uma polaridade que resulta numa relação complexa de jogos de posições, que conferem formas identitárias, sempre provisórias, de sentimentos, de pertinências ao gênero feminino ou masculino. Ou seja, mesmo num mundo que parece estar em constante mudança, as matérias prescrevem atitudes e comportamentos femininos que, apesar de parecerem diferentes e avançados, visam à manutenção de um padrão dicotômico de gênero, no qual a iniciativa feminina é bem vinda quando bem disfarçada. Aconselhase à jovem mulher a usar estratégias mais discretas para alcançar sucesso em suas investidas, uma vez 
que a iniciativa direta é um atributo indesejado aos ideais de feminilidade apresentados. Logo, as ações femininas, nesta perspectiva, envolvem o "jeitinho feminino", isto é, ações indiretas de manipulação que podem dar ao rapaz a impressão de ter sido ele o idealizador da ação posta em prática e que realizam, por fim, as aspirações femininas e masculinas.

As relações entre homens e mulheres, nas matérias analisadas, parecem sempre estar conduzindo a idéias de conjuntos entrelaçados de performances complementares entre gêneros. Cada um deles deve saber o que fazer em relação ao outro. Parece que o mais importante é a sagacidade feminina para perceber o que deve e quando deve ser desempenhado para ter sucesso nas relações com o sexo oposto, como uma coreografia com poucas variações. Isso é bastante comum nas matérias analisadas, embora, em muitos trechos, haja menção e valorização das espontaneidades nas relações. O que observamos reincidentemente nas matérias são "receitas" de modos de agir esperados, polarizados por gênero.

Consideramos que essas relações de poder, polarizadas, podem ser prejudiciais tanto a um gênero quanto ao outro, pois tais padrões cristalizam mulheres e homens em funções e modelos preestabelecidos que são geradores de angústia para quaisquer pessoas que experienciem variações de feminilidades e masculinidades. Esses padrões, ainda muito polarizados na mídia analisada, podem restringir as formas identitárias femininas e masculinas disponibilizadas como construções possíveis aos jovens, não possibilitando, assim, vivências de relações mais saudáveis, mais satisfatórias e mais enriquecedoras.

\section{Referências}

ANDRADE, S. dos S. Mídia impressa e educação de corpos femininos. In: LOURO, G. L et al. Corpo, gênero e sexualidade: um debate contemporâneo na educação. Petrópolis: Vozes, 2003. p. 108-123.

ÁVILA, M. B.; CORREA, S. O. O movimento de saúde e direitos reprodutivos no Brasil: revisitando percursos. In: GALVÃO, L.; JUAN, D. Saúde sexual reprodutiva no Brasil. São Paulo: Hucitec: Population Council, 1999. p. 70-103.
BADINTER, E. Sobre a identidade masculina. Rio de Janeiro: Nova Fronteira, 1993.

BASSANEZI, C.; URSINI, B. L. O cruzeiro e as garotas. Cadernos Pagu, Campinas, n. 4, p. 243-26o, 1995.

BASSANEZI, C. Revistas femininas e o ideal de felicidade conjugal (1945-1964). Cadernos Pagu, Campinas, n. 1, p. 111-148, 1993.

BASSANEZI, C. Mulheres nos anos dourados. In: DEL PRIORE, M. (Org.); BASSANEZI, C. (Coord.). História das mulheres no Brasil. São Paulo: Contexto: Ed. Unesp, 1997. p. 6o7-639.

BAUER, M. W.; AARTS, B. A construção do corpus: um princípio para a coleta de dados qualitativos. In:

BAUER, M. W.; GASKELL, G (Ed.). Pesquisa

qualitativa com texto, imagem e som: um manual prático. Petrópolis: Vozes, 2002. p. 39- 62.

BAUMAN, Z. Identidade: entrevista a Benedetto Vecchi. Rio de Janeiro: J. Zahar, 2005.

BRASIL. Ministério da Saúde. Secretaria de Políticas de Saúde. Projeto Promoção da Saúde. As Cartas da Promoção da Saúde. Brasília, DF, 2002. (Série B, Textos Básicos em Saúde).

BUITONI, D. H. S. Mulher de papel: a representação da mulher na imprensa feminina brasileira. São Paulo: Loyola, 1981.

CAPRICHO. São Paulo: Abril, n. 893, 28 jul. 2002a. CAPRICHO. São Paulo: Abril, n. 898, o6 out. 2002b. CAPRICHO. São Paulo: Abril, n. 902, o1 dez. 2002c. COULTHARD-CALDAS, C. R. O picante sabor do proibido: narrativas pessoais e transgressão In: FUNCK, S. B.; WIDHOLZER, N. R. (Org.). Gênero em discursos da mídia. Florianópolis: Ed. Mulheres; Santa Cruz do Sul: EDUNISC, 2005. p. 121-146.

COUTO,W. G. dos S.; MEANDRO, P. R. M. Imagens da adolescência feminina na Revista Capricho. Revista Brasileira de Crescimento e Desenvolvimento Humano, São Paulo, v. 13, n. 1, p. 63-78, 2003.

DENZIN, N. K.; LINCOLN, Y. S. Introduction: the discipline and practice of qualitative research. In: DENZIN, N. K.; LINCOLN, Y. S. Handbook of qualitative research. Thousand Oaks: Sage, 2000. p.1-28. 
DESLANDES, S. F.; GOMES, R. A pesquisa qualitativa nos serviços de saúde: notas teóricas. In: Bosi, M. L.; Mercado, F. J. (eds.). Pesquisa qualitativa de serviços de saúde. Vozes, Petrópolis, p. 99-120, 2004.

DUBAR, C. La crisis de las identidades: la interpretación de una mutación. Barcelona: Bellaterra, 2002. (Serie General Universitaria).

EDITORA ABRIL. Disponível em: <http:// www.abril.com.br>. Acesso em: 9 abr. 2003.

EDITORA ALTO ASTRAL. Disponível em: $<\underline{\text { http:// }}$ www.editoraaltoastral.com.br $>$. Acesso em: 9 abr. 2003.

FIGUEIRA, M. L. M. A revista Capricho e a produção de corpos adolescentes femininos In: LOURO, G.L et al. Corpo,Gênero e Sexualidade: Um debate contemporâneo na Educação Petrópolis: Editora Vozes, 2003, p. 124-135.

FLICK, U. Introducción a la investigación cualitativa. Madrid: Morata, 2002.

FRAGA, A. B. A boa forma de João e o estilo de vida de Fernanda In: LOURO, G. L. et al. Corpo,Gênero e Sexualidade: Um debate contemporâneo na Educação Petrópolis: Editora Vozes, 2003, p. 95-107.

GIDDENS, A. Modernidade e identidade. Rio de Janeiro: J. Zahar, 2002.

Grupo de Mídia de São Paulo. Disponível em: <http:// www.gm.org.br>. Acesso em: 9 abr. 2003.

HEISE, L. L.; ELIAS, C. Transforming Aids prevention to meet women's needs: a focus on developing countries. Social science \& medicine, Great Britain, v. 40, n. 7, p. 931-943, 1995.

KELLNER, D. A cultura da mídia - estudos culturais: identidade e política entre o moderno e o pósmoderno. Bauru: EDUSC, 2001. (Coleção Verbum).

LIPOVETSKY, G. A terceira mulher: permanência e revolução do feminino. São Paulo: Companhia das Letras, 2000.

LOURO, G. L. Gênero, sexualidade e educação: uma perspectiva pós-estruturalista. Petrópolis: Vozes, 1997.
MARCELLO, F. A. Dispositivo da maternidade: a fecundidade dos saberes na mídia contemporânea. In: FUNCK, S. B.; WIDHOLZER, N. R. Gênero em discursos da mídia. Florianópolis: Ed. Mulheres; Santa Cruz do Sul: EDUNISC, 2005. p. 121-146.

MARCONDES, W. B. A convergência de referências na promoção da saúde. Saúde e Sociedade, São Paulo, v. 13, n. 1, p. 5-13, jan./abr. 2004.

MATOS, A. A. Feminilidades e Gênero: Re-Lendo Claúdia e Nova. Revista Ciências Humanas. Taubaté: UNITAU, vol.o8, no.1, $1^{\circ}$. Semestre de 2002.

MIRANDA-RIBEIRO, P.; MOORE, A. Já nas bancas: a saúde reprodutiva das adolescentes vista através das revistas Querida e Capricho. Revista Brasileira de Estudos de População, São Paulo, v. 19, n. 2, p. 236$276,2002$.

NAVARRO, P.; DÍAZ, C. Análisis de contenido. In: DELGADO, J. M.; GUTIÉRREZ, J. Métodos y técnicas cualitativas de investigación en Ciencias Sociales. Madrid: Síntesis, 1995. p. 177-224.

NAVARRO-SWAIN, T. Feminismo e recortes do tempo presente. Revista São Paulo em Perspectiva, São Paulo: Fundação SEADE, v. 15, n. 3, p. 67-81, 2001. OLIVEIRA, N. A. S. Representações de beleza feminina na imprensa: uma leitura a partir das páginas de o cruzeiro, Cláudia e Nova (1960/1970) In: FUNCK, S. B.; WIDHOLZER, N. R. (org.): Gênero em discursos da mídia. Florianópolis: Ed. Mulheres / Santa Cruz do Sul: EDUNISC, 2005. p. 121-146

RITCHIE, J.; SPENCER, L. Qualitative data analysis for apllied policy research. In: HUBERMAN, A. M.; MILLES, M. B. The qualitative researcher's companion. Londres: Sage, 2002. p. 305-330.

ROSO, A. STREY, M. N, GUARESCHI, P. et al. Cultura e ideologia: a mídia revelando estereótipos raciais de gênero. Psicologia e Sociedade. 2002, vol. 14, no. 2, p. 74-94.

SANTOS, T. C. De Dona Letícia a Carmen da Silva: as revistas femininas e a modificação do comportamento da mulher: In: FIGUEIRA, S. (org.) Uma nova família/ o moderno e o arcaico na família de classe média brasileira. Rio de Janeiro: Jorge Zahar Editor, 1986, p. 83-98. 
SARTI, C.; MORAES, M. Q. Aí a porca torce o rabo In: BRUSCHINI, M. C. A.. ROSEMBERG, F. Vivência: história, sexualidade e imagens femininas. São Paulo: Brasiliense, 1980, p.19-57.

SCHWANDT, T. A. Three epistemological stances for qualitative inquiry: interpretivism, hermeneutics, and social constructionism. In: DENZIN, N. K.; LINCOLN, Y. S. Handbook of qualitative research. Thousand Oaks: Sage, 200o. p. 189-213.

SERRA,G. M. A; SANTOS, E. M. Saúde e mídia na construção da obesidade e do corpo perfeito. Ciência e Saúde Coletiva, Rio de Janeiro, 2003; v. 8, n. 3 , p. 691-701.

SGARBIERI, A. N. Mídia, ideologia e preconceito: Análise do Discurso Crítica In: FUNCK, S. B.; WIDHOLZER, N. R. (org.): Gênero em discursos da mídia. Florianópolis: Ed. Mulheres /Santa Cruz do Sul: EDUNISC, 2005. p.121-146.

SILVERMAN, D. Analyzing talk and text. In: DENZIN, N. K.; LINCOLN, Y. S. Handbook of qualitative research. Thousand Oaks: Sage, 2000. p. 821-834.

STRASBURGER, V. C. Os adolescentes e a mídia: impacto psicológico. Porto Alegre: Artes Médicas, 1999.
TODATEEN. Bauru: Alto Astral, n. 81, ago. 2002a. TODATEEN. Bauru: Alto Astral, n. 82, set. 2002b. TODATEEN. Bauru: Alto Astral, n.83, out. 2002c. SCOTT, J. W. Gender: a useful category of historical analysis. SCOTT, J. W. In:. Gender and the politics of history. New York: Columbia University, 1988. p. 28-50.

THOMPSON, J. B. Ideologia e cultura moderna: teoria social crítica na era dos meios de comunicação de massa. Petrópolis: Vozes, 1990.

THOMPSON, J. B. A mídia e a modernidade: uma teoria social da mídia. 5. ed. Petrópolis: Vozes, 2002.

VALLES, M. S. Técnicas cualitativas de investigación social: reflexión metodológica y práctica profesional. Madrid: Síntesis, 1997.

XAVIER, R. Representação social e ideologia: conceitos intercambiáveis?. Psicologia \& Sociedade, Porto Alegre, July/Dec. 2002, vol.14, no.2, p. 18-47

WEBER, M. Metodologia das Ciências Sociais: parte 1. 2. ed. São Paulo: Cortez; Campinas: Unicamp, 1993.

WEBER, M. Metodologia das Ciências Sociais: parte 2. 2. ed. São Paulo: Cortez; Campinas: Unicamp, 1995. 